\title{
Cryogenically Cooled Monochromator Thermal Distortion Predictions*
}

\author{
Gordon Tajiri, ${ }^{\dagger}$ Wah-Keat Lee, ${ }^{\dagger}$ Patricia Fernandez, ${ }^{\dagger}$ Dennis Mills, ${ }^{\dagger}$ \\ Lahsen Assoufid, ${ }^{\dagger}$ and Farid Amirouche ${ }^{t \dagger}$ \\ ${ }^{\dagger}$ Experimental Facilities Division, Advanced Photon Source, \\ Argonne National Laboratory, Argonne, IL 60439
}

${ }^{\dagger \dagger}$ Department of Mechanical Engineering, University of Illinois at Chicago, Chicago, Il 60607

October 1999

The submitted manuscript has been created by
the University of Chicago as Operator of
Argonne National Laboratory ("Argonne") under
Contract No. W-31-109-ENG-38 with the U.S.
Department of Energy. The U.S. Government
retains for itself, and others acting on its behalf,
a paid-up, nonexclusive, irrevocable worldwide
license in said article to reproduce, prepare
derivative works, distribute copies to the public,
and perform publicly and display publicly, by
or on behalf of the Govermment.

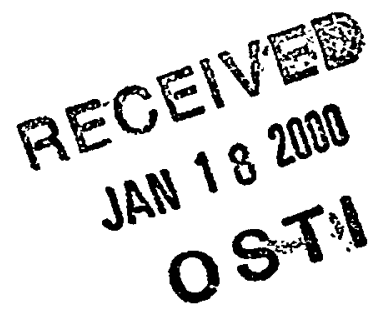

To be published in the Proceedings of the $11^{\text {th }}$ U.S. National Synchrotron Radiation Instrumentation Conference (SRI'99), Stanford, CA, October 13-15, 1999.

\footnotetext{
*This work is supported by the U.S. Department of Energy, Basic Energy Sciences, Office of Science, under contract \#W-31-109-ENG-38.
} 


\section{DISCLAIMER}

This report was prepared as an account of work sponsored by an agency of the United States Government. Neither the United States Government nor any agency thereof, nor any of their employees, make any warranty, express or implied, or assumes any legal liability or responsibility for the accuracy, completeness, or usefulness of any information, apparatus, product, or process disclosed, or represents that its use would not infringe privately owned rights. Reference herein to any specific commercial product, process, or service by trade name, trademark, manufacturer, or otherwise does not necessarily constitute or imply its endorsement, recommendation, or favoring by the United States Government or any agency thereof. The views and opinions of authors expressed herein do not necessarily state or reflect those of the United States Government or any agency thereof. 


\section{DISCLAIMER}

Portions of this document may be illegible in electronic image products. Images are produced from the best available original document. 


\title{
Cryogenically Cooled Monochromator Thermal Distortion Predictions
}

\author{
Gordon Tajiri", Wah-Keat Lee", Patricia Fernandez", Dennis Mills", \\ Lahsen Assoufid*, and Farid Amirouche ${ }^{\dagger}$ \\ Experimental Facilities Division, Advanced Photon Source, \\ Argonne National Laboratory, Argonne, Illinois 60439 \\ ${ }^{\dagger}$ Department of Mechanical Engineering, \\ University of Illinois at Chicago, Chicago, Illinois 60607
}

\begin{abstract}
Silicon crystal monochromators at cryogenic temperatures have been used with great success at third-generation synchrotron radiation sources. ${ }^{1,2}$ At the Advanced Photon Source (APS) the unique characteristics of silicon at liquid nitrogen temperatures $\left(77^{\circ} \mathrm{K}\right)$ have been leveraged to significantly reduce the thermally induced distortions on beamline optical components. Finite element simulations of the nonlinear (temperature-dependent material properties) thermal stress problem were performed and compared with the experimental measurements. Several critical finite element modeling considerations are discussed for their role in accurately predicting the highly coupled thermal and structural response of the optical component's surface distortion to the high thermal heat flux. Depending on the estimated convection heat transfer coefficient, the final refined finite element model's predictions correlated well with the experimental measurements.
\end{abstract}

\section{INTRODUCTION}

The thermal distortions of cryogenically cooled silicon crystal monochromators have been measured and characterized for various total incident powers and power densities by the Synchrotron Radiation Instrumentation - Collaborative Access Team, SRI CAT, at the APS. ${ }^{3}$ This experimental work has shown that localized distortion in the beam footprint is highly dependent on the characteristics of the beam and the incident angle, e.g., the distribution of the absorbed power as the beam travels through the crystal. To aid in the design of future optical components, a predictive tool/methodology needs to be developed that is able to (i) accurately model the complex/detailed design geometry and (ii) simulate and solve for nonuniform thermal loading and nonlinear material properties. Results from the computer simulations correlated well with the thermal distortions measurements made at the APS.

\section{PROCEDURE}

The current APS cryo-cooled silicon monochromator is shown in Figure 1. The depth of the slot is about half of the depth (z-direction) of the crystal. This slot was included to reduce the total absorbed energy of the beam in the monochromator by allowing 
more energy to be transmitted. The assumptions for these simulations were as follows: (i) discrete, depth-dependent, volumetric thermal loading; (ii) half-model assumption due to symmetry; (iii) uniform forced convection cooling at the surfaces of the coolant ports; (iv) symmetry boundary conditions at the symmetry plane; and (v) mechanical constraints at seals to allow for expansion or contraction, without rigid body motion.

To reduce the computational time required to solve the full nonlinear thermal-stress problem, a simplified model with a single port was created. A comparison between the detailed 7-port FEA model and the simplified model is given in Figure 2. The peak temperatures within the footprint of the beam between the detailed and simplified models indicated that there is a negligible loss in the accuracy $(<2 \%)$.

Zhang ${ }^{4}$ has used a 2-dimensional spatially dependent application of the thermal heat load as an area flux on the surface of the optical component to characterize the thermal distortion in the area of the beam's footprint. This loading assumes that all the energy is absorbed at or very near the surface. A more accurate approach, discussed by Assoufid et al., 5 is to consider the loading as discrete, distributed volumetric heat generation loads of the total power absorbed by the silicon crystal as the beam passes through the crystal.

$\mathrm{XOP}$, a computer simulation tool used to predict $\mathrm{x}$-ray beam interaction with various materials and surfaces, was used to determine the amount of absorbed power at different distances below the surface of the silicon crystal. The results from this calculation for APS undulator $A$ at $11 \mathrm{~mm}$ gap $(\mathrm{k}=2.6)$ were calculated for normal

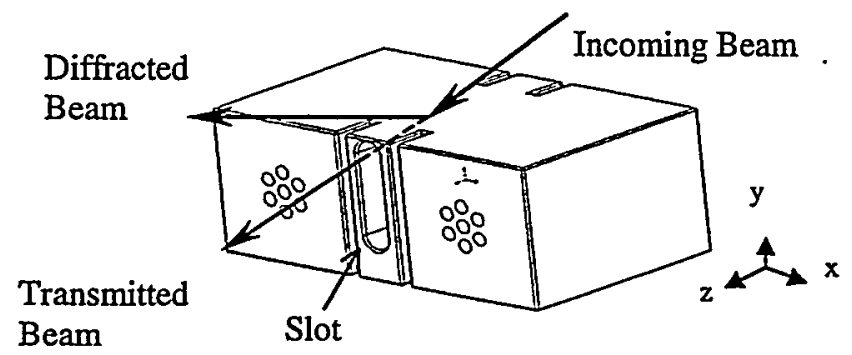

FIGURE 1. Silicon monochromator geometry and incident beam $(\mathrm{x}=85 \mathrm{~mm}, \mathrm{y}=35 \mathrm{~mm}, \mathrm{z}=50 \mathrm{~mm})$
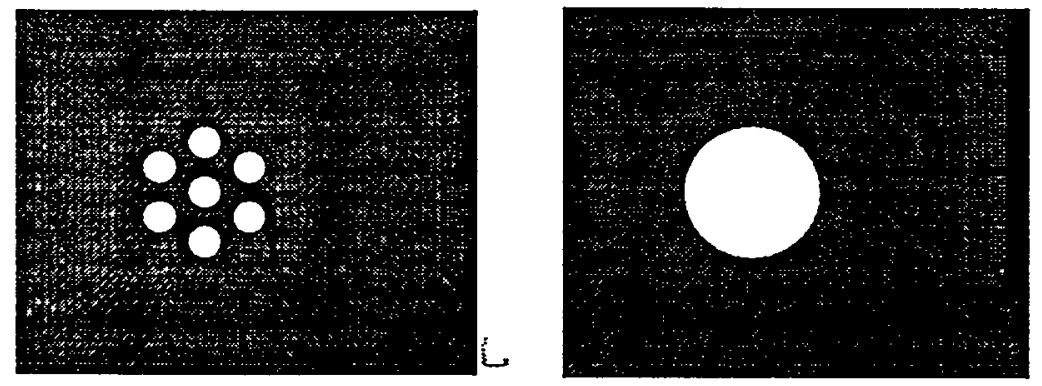

FIGURE 2. Finite element half-model comparison - front views y of the 7-port FEA model and the simplified model 


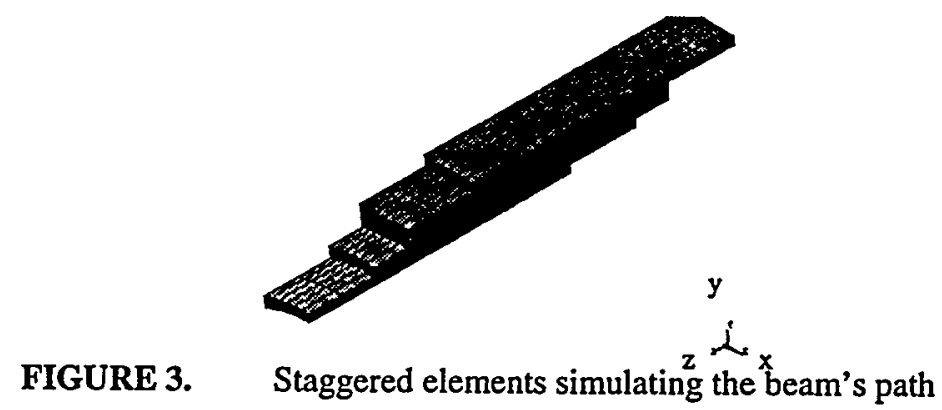

incidence at the silicon surface. The predicted distribution of absorbed power revealed that although a large percentage of the total absorbed power occurred in a region near the surface, e.g., at traversed depths less than about $1.0 \mathrm{~mm}$, an approximately equal amount is absorbed at traversed depths greater that $1.0 \mathrm{~mm}$. A more accurate representation of the thermal loading is achieved by breaking the single uniform surface or volumetric load into multiple discrete volumes that are staggered to simulate the beam's path as it travels through the crystal. XOP was used to determine the normal incident absorbed power in $1.0 \mathrm{~mm}$ increments along the path of the beam. In the finite element model, this corresponds to the distance from the surface of the crystal along the path of the beam $\left(\theta=14.3^{\circ}, 8 \mathrm{keV}\right)$. The results from the XOP calculation were then used as uniform volumetric thermal loads for each layer of the finite element model. The geometry assumed for the staggered elemental volumes $(0.24 \mathrm{~mm}$ thick) is given in Figure 3.

The forced convection coefficient, $h$, of the liquid nitrogen for a given flow rate through the actual multiple coolant port design was determined from the relationship

$$
h=N u \frac{k}{D} \text {, }
$$

where $\mathrm{Nu}$ is the Nusselt number for simultaneously developing velocity and temperature fields after a square entrance, $k=k(T)$ is the thermal conductivity of liquid nitrogen, and $\mathrm{D}$ is the diameter of the port. The correlation for the Nusselt number was determined by Molki et al. ${ }^{6}$ for various entrance configurations. Based on their work and for a flow rate of 7 liters/min., a good estimate of the convection cooling coefficient is $9,000 \mathrm{~W} / \mathrm{m}^{2}-{ }^{\circ} \mathrm{K}$.

\section{RESULTS}

The slope error was calculated from the vertical displacements of the nodes along the center of the beam, where the surface distortion is maximum. A family of constant convection coefficient curves, comparing the maximum thermal distortions for a range of absorbed powers, is shown in Figure 4.

A comparison of these analytical results with the experimental results from actual experimental measurements made by Lee et al. ${ }^{3}$ at the APS is consistent. Several 


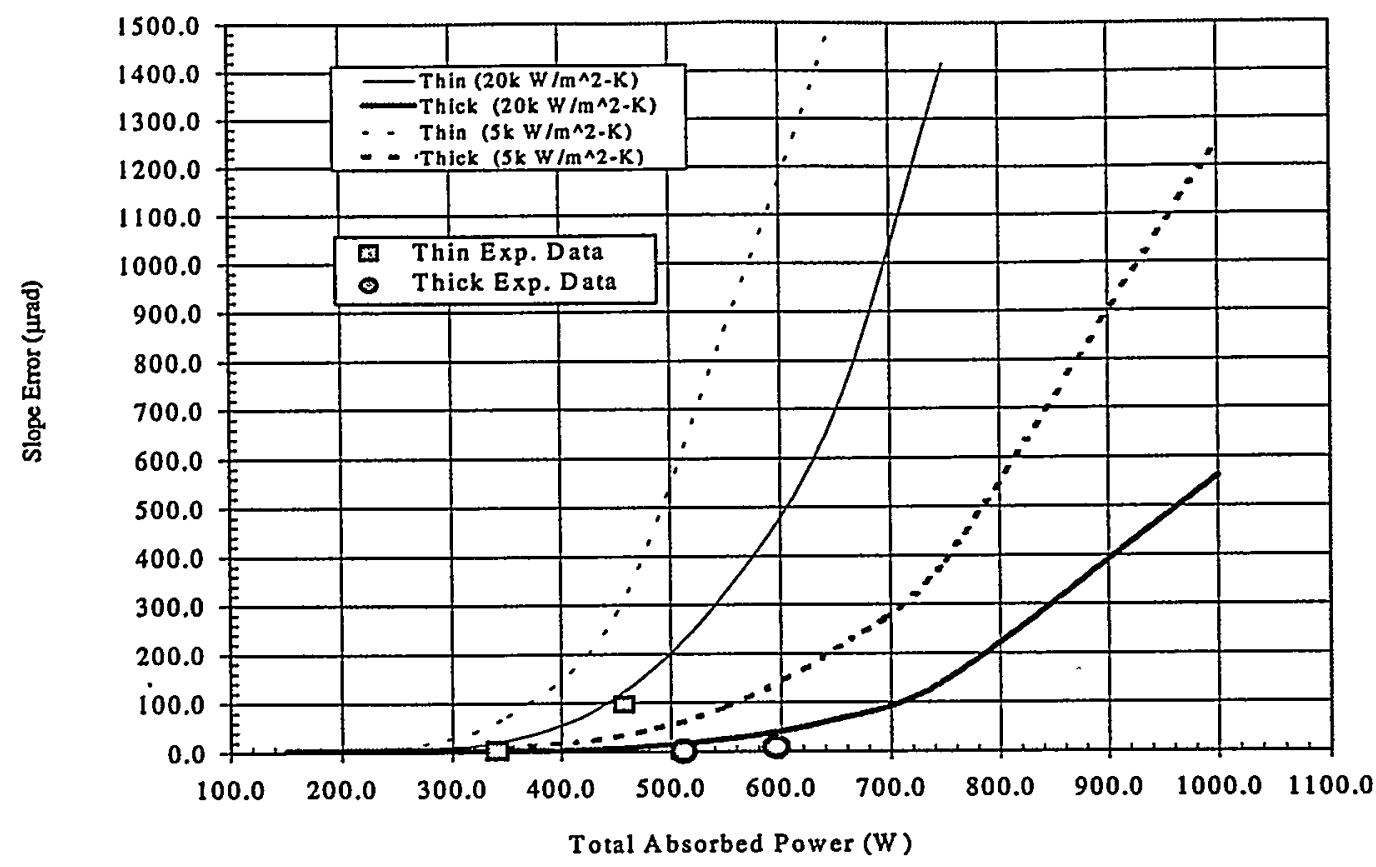

FIGURE 4. Comparison of thick-section and thin-section thermal distortions

experimental data points have been plotted in Figure 4. Depending on the convection coefficient, the limited experimental data correlates well with the FEA predictions.

\section{ACKNOWLEDGMENTS}

This research was supported by the U. S. Department of Energy, BES-Material Science, under Contract No. W-31-109-ENG-38.

\section{REFERENCES}

1. Anthony, F., High Heat Load Optics: An Historical Overview, Optical Engineering, Vol. 34, pp. 313-320, 1995.

2. Marot, G., Cryogenic Cooling of High Heat Load Optics, Optical Engineering, Vol. 34, pp. 426-431, 1995.

3. Lee, W.-K., Fernandez, P., Mills, D. M., Performance Limits of Direct Cryogenically Cooled Silicon Monochromators - Experimental Results at the APS, Submitted to J. Synchrotron Rad.

4. Zhang, L., Cryogenic Cooled Silicon-Based X-ray Optical Elements - Heat Load Limit, SPIE Vol. 1997, High Heat Flux Engineering II, 1993, pp. 223-235.

5. Assoufid, L., Lee, W.-K., and Mills, D.M. , A Finite Element Analysis of Room Temperature Silicon Crystals for the Advanced Photon Source Bending-Magnet and Insertion-Device Beams, Argonne National Laboratory Report, ANL/APS/TB-19, 1994.

6. Molki, M. and Sparrow, E. M., An Empirical Correlation for the Average Heat Transfer Coefficient in Circular Tubes, J. Heat Transfer, Vol. 27, pp. 669-675, 1984. 